The Journal of

Thoracic and Cardiovascular

Surgery

Vol 127, No. 1, January 2004

\title{
Gender and valvular surgery
}

Rita F. Redberg, MD, MSc

Nelson B. Schiller, MD

See related editorial on page 4 .

From the University of California, San

Francisco, Department of Medicine, San Francisco, Calif.

Received for publication Aug 8, 2003; accepted for publication Sept 9, 2003

Address for reprints: Dr R. F. Redberg, Director, Women's Cardiovascular Services, School of Medicine, Division of Cardiology, 505 Parnassus Ave, Suite M-1180, San Francisco, CA 94143-0124 (E-mail: redberg@medicine.ucsf.edu).

J Thorac Cardiovasc Surg 2004;127:1-3

$0022-5223 / \$ 30.00$

Copyright () 2004 by The American Association for Thoracic Surgery

doi:10.1016/j.jtcvs.2003.09.022

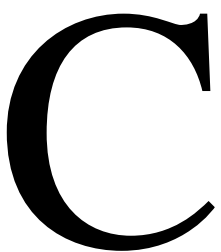

ardiovascular disease is currently the leading cause of death among American women. Although the majority of these deaths can be attributed to coronary artery disease, a significant number of women have valvular heart disease. In fact, of 123,000 patients discharged from the hospital in 1987 with diagnoses of aortic or mitral valve disease, $71 \%$ were women. ${ }^{1}$ In addition, more than $60 \%$ of heart valve replacement procedures are performed in women. In contrast, $39 \%$ of patients discharged from the hospital with diagnoses of myocardial infarction (MI) were women. ${ }^{2}$ Thus, while men are 15 times more likely to be discharged with diagnoses of MI, women are just 4 times more likely to be discharged with diagnoses of MI than vascular disease. ${ }^{1}$

\section{Gender Differences in Pathophysiology of Valvular Heart Disease}

Gender differences affect the pathophysiology of valvular heart disease. Women have a 5\% to $10 \%$ higher cardiac output (CO) at any level of submaximal oxygen uptake than do men. The difference may be attributed to women's lower hemoglobin levels $(\sim-10 \%)$. Women also have a maximal aerobic capacity that is $50 \%$ lower than that of men (10\%-15\% lower when adjusted for lean body mass), which may be related to lesser blood volume. In addition, women have greater capacity to perform isotonic exercise, possibly because the estrogen influence on fatty acid is a preferential energy substrate during exercise and sparing of glycogen stores.

Such gender differences have important implications in the care of women with valvular heart disease. For example, because women are on average smaller than men, it is best to index for body size when doing valve calculations. Also, women's higher CO means a higher valve gradient, which is important when calculating valve area.

\section{Pregnancy}

Normal pregnancy is associated with a $30 \%$ to $50 \%$ increase in blood volume and a related increase in $\mathrm{CO}$. The volume changes begin in the first trimester and peak by 20 to 24 weeks. ${ }^{3}$ Concurrently, heart rate increases by 10 to 20 beats per minute and the stroke volume increases. Also, there is a substantial reduction in systemic vascular resistance and a decrease in blood pressure. Clinically significant maternal heart disease is uncommon during pregnancy (prevalence, $<1 \%$ ), ${ }^{4}$ but it does increase the risk of adverse maternal, fetal, and neonatal outcomes ${ }^{5}$; ideally, patients are aware of their valvular condition and prenatal risk when they are deciding whether to have children. Both the American Heart Association and the American College of Cardiology have classified maternal and fetal risk during pregnancy on the basis of the type of valvular abnormality and by New York Heart Association (NYHA) functional class. ${ }^{6}$ 
Current guidelines state that moderate to severe valvular stenosis (either mitral or aortic) is poorly tolerated during pregnancy. Likewise, mitral or aortic regurgitation (with NYHA class III-IV symptoms) increases risk because of the increased volume load and CO during pregnancy.

\section{Mitral Stenosis}

There are gender differences in the pathophysiology of mitral stenosis (MS), with a 3:1 female preponderance for the condition. Calcification of the valves tends to occur later in women than in men, providing a longer time window in which balloon valvuloplasty can be performed, and perhaps explaining why $82 \%$ of all mitral balloon valvuloplasty candidates are women.

\section{Mitral Stenosis and Pregnancy}

Management of MS during pregnancy can be challenging, and congestive heart failure, along with atrial fibrillation, often may first appear with pregnancy, which can lead to systemic embolism. If symptoms persist during the first trimester despite diuretics, pregnancy may not be tolerated. Therapeutic options (termination or valvuloplasty) must be considered. Beta-blockers slow the maternal heart rate and control symptoms, but these agents cross the placenta and may also slow the fetal heart rate. Maternal mortality in patients with severe MS is 5\%. Labor, delivery, and the immediate postpartum period are the times of greatest risk of death. Surgery for MS can be performed during pregnancy, but there is a fetal death rate of $10 \%$.

High-risk patients, such as those with severe symptoms (NYHA class III or IV) or tight mitral stenosis (valve area $<1.0 \mathrm{~cm}^{2}$ ), who undergo balloon mitral valvuloplasty or valve surgery ${ }^{7}$ before conceiving appear to have fewer complications during pregnancy than do women who are treated medically. Women with severe symptoms during pregnancy have undergone successful percutaneous balloon mitral valvuloplasty during the second trimester, with normal subsequent deliveries and excellent fetal outcomes. ${ }^{8}$ Because radiation is of particular concern during pregnancy, women who must be exposed to radiation during valvuloplasty procedures should have their uterus shielded and be informed about the possible risks. Alternatively, mitral valvuloplasty can be performed with transesophageal echocardiographic guidance, reducing radiation risk. Pregnant women with severe MS have also undergone open cardiac surgery; maternal outcomes are similar to those of nonpregnant patients, but the fetus may be lost in $10 \%$ to $30 \%$ of cases. $^{9}$

\section{Aortic Valve Disease}

Aortic valve disease, such as bicuspid aortic valve, nonrheumatic valvular aortic stenosis, and diseases of the aorta have a nearly 3:1 male predominance in clinical and autopsy studies. ${ }^{10-12}$

\section{Mitral Valve Prolapse}

Early studies suggest a symptom complex for mitral valve prolapse (MVP) that includes chest pain, dyspnea, palpitations, syncope, anxiety, panic attacks, bony thoracic abnormalities, asthenic habitus, and echocardiographic abnormalities. ${ }^{13-15}$ However, more recent and rigorous studies have cast doubt that these findings are more common in MVP than in control subjects. Data from the Framingham study suggest that people with MVP display a far more benign profile of associated valvular, atrial, and ventricular abnormalities than previously reported in hospital- or referralbased series. ${ }^{16}$ Another study from Cornell compared firstdegree relatives of MVP to first-degree relatives of their unaffected spouse and found differences in midsystolic clicks, thoracic abnormalities, and palpitations but not atypical chest pain, dyspnea, panic attacks, trait anxiety score, and electrocardiogram-inferior abnormalities. ${ }^{17}$ Thus, it appears that the use of nonrigorous criteria, such as 4-chamber echocardiography, led to the condition being overdiagnosed. Newer criteria by Levine and colleagues ${ }^{18}$ have allowed for the more accurate and less frequent diagnosis of MVP. These criteria, combined with the recognition of the benign nature of MVP (especially in women) and the attendant problems to labeling valvular variants as a disease, have led to a decrease in the number of MVP diagnoses.

\section{Use of Prosthetic Valves in Pregnancy}

Mechanical prostheses present particular disadvantages for women of childbearing age because they require a rigorously maintained, noncoumadin anticoagulation regimen such as unfractionated or low-molecular-weight heparin during pregnancy (coumadin is a known teratogen). Despite careful anticoagulation, there remains a high risk for thromboembolism and fetal hemorrhage. In addition, there is an $18 \%$ structural valve failure rate in pregnant women with bioprosthetic valves. Prosthetic valve failure in the mitral position occurs approximately 2.5 to 8 years earlier than expected in the life span of the prosthesis. ${ }^{19}$

\section{Summary}

Because of differences in pathophysiology and body size, as well as the special considerations during pregnancy, management and outcomes for valvular surgery differ in women. Overall, rates of rheumatic heart disease continue to fall, as do valve replacements related to rheumatic disease. Continued research is necessary to optimize our care of women with valvular disease, particularly the challenging care of women with serious valvular heart disease during pregnancy. 


\section{References}

1. Graves E. Detailed diagnoses and procedures. Washington, DC: Department of Health and Human Services; 1995. p. 89-1761.

2. Vongpatanasian WHL, Lange RA. Prosthetic heart valves. $N$ Engl J Med. 1996;335:407-16.

3. van Oppen AC, van der Tweel I, Alsbach GP, et al. A longitudinal study of maternal hemodynamics during normal pregnancy. Obstet Gynecol. 1996;88:40-6.

4. Siu SC, Sermer M, Colman JM, et al. Prospective multicenter study of pregnancy outcomes in women with heart disease. Circulation. 2001; 104:515-21.

5. Siu SC, Colman JM, Sorensen S, et al. Adverse neonatal and cardiac outcomes are more common in pregnant women with cardiac disease. Circulation. 2002;105:2179-84.

6. Task Force on Practice Guidelines (Committee on Management of Patients with Valvular Heart Disease). ACC/AHA guidelines for the management of patients with valvular heart disease. A report of the American College of Cardiology/American Heart Association. J Am Coll Cardiol. 1998;32:1486-588.

7. Stephen SJ. Changing patterns of mitral stenosis in childhood and pregnancy in Sri Lanka. J Am Coll Cardiol. 1992;19:1276-84.

8. Fawzy ME, Kinsara AJ, Stefadouros M, et al. Long-term outcome of mitral balloon valvotomy in pregnant women. J Heart Valve Dis. 2001;10:153-7.

9. Bernal JM, Miralles PJ. Cardiac surgery with cardiopulmonary bypass during pregnancy. Obstet Gynecol Surv. 1986;41:1-6.
10. Roberts WC. The congenitally bicuspid aortic valve. A study of 85 autopsy cases. Am J Cardiol. 1970;26:72-83.

11. Campbell M. Calcific aortic stenosis and congenital bicuspid aortic valves. Br Heart J. 1968;30:606-16.

12. Hahn RT, Roman MJ, Mogtader AH, et al. Association of aortic dilation with regurgitant, stenotic and functionally normal bicuspid aortic valves. J Am Coll Cardiol. 1992;19:283-8.

13. Popp RL, Winkle RA. Mitral-valve prolapse syndrome. JAMA. 1976; 236:867-70.

14. Beton DC, Brear SG, Edwards JD, et al. Mitral valve prolapse: an assessment of clinical features, associated conditions and prognosis. $Q$ J Med. 1983;52:150-64.

15. Lewis RP, Wooley CF, Kolibash AJ, et al. The mitral valve prolapse epidemic: fact or fiction. Trans Am Clin Climatol Assoc. 1986;98:22236.

16. Freed LA, Benjamin EJ, Levy D, et al. Mitral valve prolapse in the general population: the benign nature of echocardiographic features in the Framingham Heart Study. J Am Coll Cardiol. 2002;40:1298-304.

17. Devereux RB, Kramer-Fox R. Gender differences in mitral valve prolapse. Cardiovasc Clin. 1989;19:243-58.

18. Levine RA, Triulzi MO, Harrigan P, et al. The relationship of mitral annular shape to the diagnosis of mitral valve prolapse. Circulation. 1987;75:756-67.

19. Hanania G, Thomas D, Michel PL, et al. Pregnancy and prosthetic heart valves: a French cooperative retrospective study of 155 cases. Eur Heart J. 1994;15:1651-8. 